\title{
Cost-effectiveness of stimulation of the sphenopalatine ganglion (SPG) for the treatment of chronic cluster headache: a model-based analysis based on the Pathway $\mathrm{CH}-1$ study
}

\author{
Jan B. Pietzsch¹, Abigail Garner ${ }^{1}$, Charly Gaul ${ }^{2}$ and Arne May ${ }^{3 *}$
}

\begin{abstract}
Background: In the recent Pathway $\mathrm{CH}-1$ study, on-demand stimulation of the sphenopalatine ganglion (SPG) by means of an implantable neurostimulation system was proven to be a safe and effective therapy for the treatment of chronic cluster headache. Our objective was to assess the cost-effectiveness of SPG stimulation in the German healthcare system when compared to medical management.

Methods: Clinical data from the Pathway $\mathrm{CH}-1$ study were used as input for a model-based projection of the cost-effectiveness of SPG stimulation through 5 years. Medical management as the comparator treatment was modeled on the basis of clinical events observed during the baseline period of $\mathrm{CH}-1$. The costs of treatment were derived from a previously published cluster headache costing study and 2014 medication, neurostimulator, and procedure costs. We computed the 5-year incremental cost-effectiveness ratio (ICER) in euros per quality-adjusted life year (QALY), with costs and effects discounted at $3 \%$ per year.

Results: SPG stimulation was projected to add 0.325 QALYs over the study period, while adding $€ 889$ in cost, resulting in a 5-year ICER of €2,736 per QALY gained. Longer follow-up periods, higher baseline attack frequency, and higher utilization of attack-aborting medications led to overall cost savings. SPG stimulation was found either cost-effective or cost-saving across all scenarios investigated in sensitivity analyses.

Conclusions: Our model-based analysis suggests that SPG stimulation for the treatment of chronic cluster headache, under the assumption of sustained therapy effectiveness, leads to meaningful gains in health-related quality of life and is a cost-effective treatment strategy in the German healthcare system.
\end{abstract}

Keywords: Chronic cluster headache; Implantable stimulator; Stimulation; Sphenopalatine ganglion; Cost-effectiveness; Germany

\section{Background}

Treatment of chronic cluster headache $(\mathrm{cCH})$ is guided by the dual objectives of ending acute attacks and decreasing attack frequency. Current medical treatment for acute attacks includes the use of oxygen inhalation, subcutaneous or intranasal application of triptans, or intranasal lidocaine [1-3]. Preventative medications usually consist of verapamil

\footnotetext{
*Correspondence: a.may@uke.de

${ }^{3}$ Institut für Systemische Neurowissenschaften, Universitätsklinikum Hamburg-Eppendorf, Martinistr. 52, Haus S10, Zi. 318, Hamburg 20246 Germany

Full list of author information is available at the end of the article
}

or lithium as first choice; alternatively or concurrently, steroids, topiramate, melatonin, long-acting triptans, and occipital nerve blocks are also commonly used as prophylactic treatments [4-6]. The costs of such pharmaceutical treatments for $\mathrm{cCH}$ are substantial, and have previously been estimated to average $€ 15,700$ per year, with severely afflicted patients incurring even higher annual medication costs [7].

Electrical stimulation of the sphenopalatine ganglion (SPG) has recently been proposed as an alternative treatment approach for cluster headache, relying on an implantable on-demand stimulator that is activated by the 
patients themselves (PULSANTE SPG Microstimulation Therapy; Autonomic Technologies Inc. (ATI); Redwood City, California, USA). The safety and effectiveness of the PULSANTE system was first investigated in the Pathway CH-1 study, a multicenter, randomized trial [8]. This study found the therapy to have dual clinical benefits of acute pain relief and attack prevention, while demonstrating an acceptable safety profile comparable to similar surgical procedures. In recent years, further investigational and commercial experience with the system has been gained in the European Union and other markets $[9,10]$. In the EU, the PULSANTE system is available for the treatment of episodic and chronic cluster headache since obtaining CE mark approval in 2012. In the United States, a pivotal study is currently recruiting patients (NCT02168764).

Our objective in this study was to evaluate the longterm cost-effectiveness of SPG stimulation, as compared to medical management, based on the findings of the Pathway $\mathrm{CH}-1$ study and a model-based extrapolation through 5 years. We chose the German healthcare system as the setting for this analysis because of the experience already gained with SPG stimulation in that market, and the general relevance of Germany as the largest European healthcare system.

\section{Methods}

\section{Study design}

Our analysis relied on two primary sources of data. First, we used data from the Pathway $\mathrm{CH}-1$ study to estimate the therapeutic effectiveness of SPG stimulation compared to medical management. Second, we used data from a comprehensive resource utilization and costing study previously conducted on $\mathrm{CH}$ patients in the German healthcare system [7] to estimate current costs of $\mathrm{cCH}$ management in the acute phase.

For conventional medical management, resource use and health-related quality of life were estimated according to the baseline values of the Pathway $\mathrm{CH}-1$ study, prior to implantation of the SPG neurostimulator [8]. These values were assumed to remain constant throughout the period of the modeled analysis. In line with the results of the long-term data available to-date $[9,10]$, long-term effectiveness of SPG stimulation for accomplishing pain relief was assumed to remain constant over time, and to be identical to the effectiveness observed in the Pathway $\mathrm{CH}-1$ study.

For each treatment strategy, we computed the total costs as well as gains in health-related quality of life, as measured through projected gains in quality-adjusted life years (QALYs). The timeframe of the base case analysis was 5 years. We chose this comparatively short timeframe in order to balance our objective of performing a conservative analysis (in light of the fact that follow-up data are currently available for only 3 years), against the typical requirement that model-based assessments of therapies for chronic conditions employ a long-term or even lifetime perspective.

\section{Model structure and modeling framework}

The study model computed costs and QALYs for two simulated cohorts: $\mathrm{cCH}$ patients treated with SPG stimulation, and $\mathrm{cCH}$ patients treated with medical management (referred to as the control cohort). We assumed that all $\mathrm{cCH}$ attacks not successfully treated with SPG stimulation (i.e., attacks in which pain relief was not achieved within $15 \mathrm{~min}$, in line with the $\mathrm{CH}-1$ primary efficacy endpoint) would instead be treated with standard medical management.

The model further assumed that stimulation would reduce the average frequency of $\mathrm{cCH}$ attacks in the SPGtreated cohort by $31 \%$, as was observed in the Pathway $\mathrm{CH}-1$ study [8]. When considering the overall cohort of frequency responders and non-responders, we conservatively assumed that this prophylactic effect would gradually decline by $10 \%$ each year, so that the prophylactic effect would be reduced by half at 5 years of follow-up.

Our analysis had two co-primary outcome measures: the per-patient budget impact to payers; and the incremental cost-effectiveness ratio (ICER), defined as the incremental direct costs of medical treatment and consequences divided by the incremental health benefits expressed as quality-adjusted life years (QALYs). The ICER is a common metric used in health-economic analyses to assess the value of an intervention [11]. QALYs, taking into account both gains in survival and healthrelated quality of life, describe the direct patient-relevant benefits associated with a therapy or intervention [12]. Figure 1 provides an overview of the model structure and resulting outcome metrics.

The analysis took the perspective of payers in the German statutory health insurance system. Costs and health outcomes were discounted at $3 \%$ per year, in line with current guidelines for health-economic analysis [13]. All costs were actual or estimated amounts in 2014 euros. Mortality was not considered in the analysis because of the comparatively young treatment age of patients in Pathway $\mathrm{CH}-1$, the limited 5-year timeframe of the analysis, and because no significant differences in mortality were expected between the SPG stimulation and medical management cohorts.

\section{Input parameters}

The Pathway $\mathrm{CH}-1$ study and its findings have been presented elsewhere [8]. In short, that study was a prospective, randomized, blinded, multicenter trial conducted to evaluate the safety and efficacy of acute electrical stimulation of the SPG using the PULSANTE 


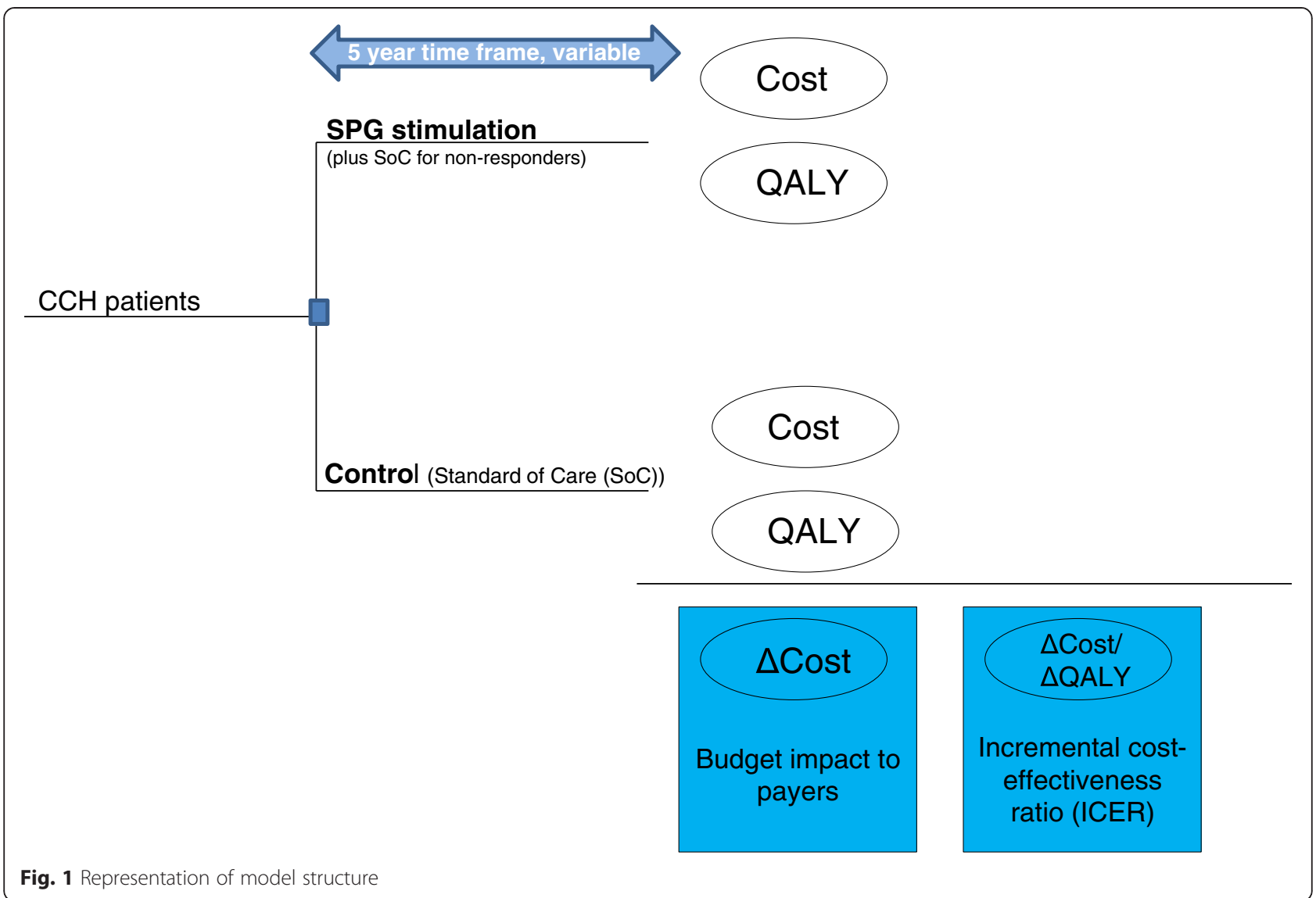

SPG Microstimulation Therapy (formerly referred to as ATI Neurostimulation System). Of note, this study exclusively recruited patients with chronic cluster headache. While inclusion criteria did not require $\mathrm{cCH}$ to be medically refractory, most of the ultimately enrolled patients were refractory. The study did not collect cost data.

For each study subject (for demographic data see Table 1), the Pathway $\mathrm{CH}-1$ trial consisted of 5 phases [8]: 1) a pre-implant period of 4 weeks to allow for establishment of subjects' baseline attack frequency; 2) a postimplant period of at least 3 weeks for recovery after implantation; 3) a therapy titration phase of at least 6 weeks, during which the stimulator was used, and the selected electrodes and stimulation parameters were individually adjusted for optimal therapy; 4) an experimental phase lasting a minimum of 3 weeks and a maximum of 8 weeks,

Table 1 Baseline characteristics of patients enrolled in the Pathway $\mathrm{CH}-1$ study [8]

\begin{tabular}{ll}
\hline Variable & Pathway CH-1 (N=28) \\
\hline Age (years) & $45(20-63)$ \\
Male gender (no.; \%) & $27(84 \%)$ \\
Baseline CH attacks per day & $2.74(0.57-10)$ \\
\hline
\end{tabular}

or the shortest period required for the treatment of 30 attacks; and 5) an open-label phase to continue collecting data through 1 year after implantation, with patients receiving full stimulation therapy at each use.

The primary endpoint for this sham-controlled study for gauging effectiveness was pain relief in the acute attack within $15 \mathrm{~min}$ after starting the stimulation, and without use of rescue medications, as defined in the study protocol. A secondary observational endpoint was the reduction of attack frequency, established by comparing the frequency of $\mathrm{cCH}$ attacks per 4 weeks at the end of the experimental period to the frequency established at baseline. Health-related quality of life was assessed using the physical (PCS) and mental (MCS) component summary scores of SF-36v2. A full list of all endpoints is provided in the published Pathway $\mathrm{CH}-1$ study [8].

Therapy effectiveness Our model assumed an attack frequency for the stimulation cohort that was $31 \%$ lower than the baseline frequency of 2.74 attacks per day. This estimate was based on the study-reported percentage of frequency reduction across the entire SPG-treated cohort (i.e., frequency responders and non-frequency-responders). The medical management 
cohort was assumed to maintain its baseline attack frequency. Over the 5-year modeling horizon, the attack frequency of the medical management cohort was assumed to remain constant, while the prophylactic effect in the SPG-treated cohort was assumed to gradually decline over time (see Table 2).

Based on the Pathway $\mathrm{CH}-1$ study protocol, we further assumed that for attacks that were successfully treated with stimulation (i.e., pain relief was accomplished within 15 min of onset), no acute rescue medication was required - in line with the definition of this endpoint, which was defined to only be met if no acute medication was taken by the patient. Conversely, it was assumed that those attacks not successfully treated through SPG stimulation did require acute rescue medications at the average doses, as described below.

In terms of therapy complications, our model takes into account device revisions that needed to be performed in $\mathrm{CH}-1$. No longer-term revisions are assumed to be required, because the SPG stimulation system does

Table 2 Model input parameters

\begin{tabular}{|c|c|c|c|}
\hline Variable & Base case & Range & Source \\
\hline \multicolumn{4}{|l|}{ Cohort characteristics } \\
\hline Age & 45 & & Pathway $\mathrm{CH}-1$ data [8] \\
\hline Male gender & $84 \%$ & & \\
\hline Clinical effectiveness & Base case & Range (\%) & Source \\
\hline Baseline $\mathrm{CH}$ attacks per day & 2.74 & \pm 50 & \multirow[t]{3}{*}{ Pathway $\mathrm{CH}-1$ data [8] } \\
\hline Pain relief with SPG stimulation (within 15 min) & $67.1 \%$ & $50.2-80.5$ & \\
\hline Frequency reduction with SPG stimulation (total cohort) & $31.0 \%$ & $\begin{array}{l}15-50 \\
\text { (assumption) }\end{array}$ & \\
\hline $\begin{array}{l}\text { Absolute decline in frequency reduction for SPG } \\
\text { stimulation, per year }\end{array}$ & $3.1 \%$ & $0-6.2$ & Author estimate \\
\hline Medication costs ${ }^{\mathrm{a}}$ & $\begin{array}{l}\text { Base case } \\
(€)\end{array}$ & Range (\%) & Source \\
\hline Oxygen [2.6* inhalation] & 257.20 & & \multirow{5}{*}{$\begin{array}{l}\text { Utilization data based on [7], frequency-adjusted to Pathway } \\
\mathrm{CH}-1 \text { cohort; } 2014 \text { unit cost data from [14] }\end{array}$} \\
\hline Zolmitriptan nasal spray [1.08 * 5 mg] & $1,118.08$ & & \\
\hline Sumatriptan s.c. $[1.30 * 6 \mathrm{mg}]$ & 2,959.64 & & \\
\hline Sumatriptan nasal spray $[1.08 * 20 \mathrm{mg}]$ & 112.62 & & \\
\hline Resulting mean medication cost per attack & 8.92 & \pm 25 & \\
\hline SPG stimulation costs & $\begin{array}{l}\text { Base case } \\
(€)\end{array}$ & Range & Source \\
\hline Implantation of SPG stimulation system (hospital inpatient) & $5,293.99$ & & $\begin{array}{l}\text { DRG B17-B, based on ICD-10-GM diagnosis code G.44 and } \\
\text { OPS procedure code 5-059.c2 }\end{array}$ \\
\hline Reimbursed cost of ATI SPG Neurostimulator & $25,000.00$ & & Estimate provided by manufacturer \\
\hline $\mathrm{CT} / \mathrm{CVT}$ imaging cost pre- and post-implant & 400.00 & & Author estimate \\
\hline $\begin{array}{l}6 \text { visits to headache center for device titration, } \\
\text { follow-up to implantation }\end{array}$ & 596.46 & & Based on cost reported in [7], adjusted to 2014 \\
\hline Revision of implant ( 4 of 32 patients) & $5,293.99$ & & $\begin{array}{l}\text { DRG B17-B, based on ICD-10-GM diagnosis code G.44 and } \\
\text { OPS procedure code 5-059.c2; implant provided by } \\
\text { manufacturer (ATI) at no additional cost [26]. }\end{array}$ \\
\hline Antibiotics for infection treatment ( 3 of 32 patients) & 94.88 & & Augmentan (amoxicillin) tablets N2 [14] \\
\hline $\begin{array}{l}\text { Device explantation, without new implantation ( } 2 \text { of } 32 \\
\text { patients, outpatient) }\end{array}$ & 355.77 & & $\begin{array}{l}\text { Ambulatory surgery reimbursement, EBM } 31,251,31,504 \text {, } \\
31,670 \text {, based on OPC code 5-028.6 [27] }\end{array}$ \\
\hline Utilities $^{\mathrm{b}}$ & Base case & Range & Source \\
\hline Baseline & 0.55 & & \multirow{5}{*}{$\begin{array}{l}\text { Approximation based on Pathway CH-1 SF-36v2 data and } \\
\text { mapping algorithm [15]; years 2-5 extrapolated }\end{array}$} \\
\hline End of experimental phase (stimulation) & 0.67 & & \\
\hline Open label (stimulation) & 0.68 & & \\
\hline 12 months (stimulation) & 0.61 & & \\
\hline Years $2-5$ estimate (stimulation) & 0.61 & & \\
\hline
\end{tabular}

a. 6 months, average total costs per patient, medical management cohort; [mean daily intake in patients taking respective medication] b. mapped EQ-5D scores, based on trial-reported SF-36 
not have a battery that needs to be replaced, a difference to other stimulation technologies such as spinal cord stimulation (SCS) and occipital nerve stimulation (ONS). Further, our analysis takes into account two device explants and oral antibiotic treatment of surgical site infections in two patients. Other adverse events listed in the $\mathrm{CH}-1$ study either did not require treatment or did not lead to additional treatment costs, and are therefore not considered in this analysis.

Costs Costs were considered from the perspective of German statutory health insurance (SHI), taking into account only direct healthcare costs. The cost of implanting the SPG stimulation system was based on the 2014 GDRG reimbursement amount defined by the ICD-10-GM diagnosis code for cluster headache, and the applicable procedure code for implantation of the neurostimulator. In addition to the DRG payment, the cost of the stimulation system itself was also taken into account, in accord with the amounts currently paid to hospitals by insurance payers. Further, we estimated the costs of pre- and postimplant imaging by computed tomography $(\mathrm{CT})$ and digital volume tomography (DVT), as well as costs for revisions, explants, and antibiotic treatment of 3 patients suffering from surgical site infection. Also, we included the costs of 6 follow-up visits to an outpatient headache center for device titration and general follow-up of the implantation procedure. Beyond these 6 visits, we assumed no differences between costs of physician visits between the stimulation and the control cohorts, although patients with effective therapy will not seek medical advice or care as often as intractable patients. Of note, all patients in the $\mathrm{CH}-1$ study were medically intractable.

Total costs for attack-aborting medications were computed on the basis of the utilization rates reported for chronic cluster headache patients in the prior costing study [7] and 2014 medication costs [14], following the same approach as that taken in the original study. For the medical management cohort of our model, the resulting cost for attack-aborting medication was $€ 8,892$ per year ( $€ 171$ per week). This value reflects the lower attack frequency of 2.74 attacks per day in the Pathway $\mathrm{CH}-1$ study [8], compared to 3.80 in the costing study [7]. We did not consider costs for preventative medications, as these do not differ between the two cohorts, and therefore do not influence the results of our incremental analysis.

Health-related quality of life Utility estimates were derived as follows. Short-Form 36v2 (SF-36) health profile data was collected alongside the Pathway $\mathrm{CH}-1$ study. We used an established mapping algorithm [15] to convert the mean statistics of the 8 dimension scores of the SF-36 into mean cohort EQ-5D preference-based index scores. The SF-36v2 forms were available to $\mathrm{CH}-1$ study participants at baseline, at the end of the experimental period, and during the open-label period, as well as during follow-up at 12, 15, 18, 21, and 24 months.

For the simulated medical treatment cohort, we assumed the baseline utility would be maintained over the full timeframe of the analysis. For the stimulation cohort, we determined utility projections in 4-week increments based on the mapped EQ-5D scores at the reported time points up to 24 months. For the period from 3 to 5 years, we assumed quality of life to be constant at the average of the year-projected scores between 12 and 24 months, thus extrapolating the average quality of life observed in year 2 to years 3,4 , and 5 .

The utility values were subsequently used in the analysis to compute quality-adjusted life years (QALYs) for both the medical management and stimulation cohorts.

\section{Analysis of uncertainty}

Comprehensive one-way sensitivity analyses were conducted to evaluate the effects of parameter uncertainty, including variations in the effectiveness of SPG stimulation. The parameter ranges were derived from the published Pathway $\mathrm{CH}-1$ results, prior published data, and from expert opinion where applicable (see Table 2).

\section{Results and discussion \\ Base case results}

Over the 5-year time horizon of the analysis, discounted total direct medical costs for the SPG stimulation cohort were $€ 42,187$, compared to $€ 41,298$ for the simulated medical management cohort, for a total additional cost of $€ 889$.

Health-related quality of life for the stimulation cohort, estimated on the basis of subjects' SF-36 scores mapped to EQ-5D preference scores, was 0.548 at baseline, 0.668 at the end of the experimental period, 0.675 during the open-label period, and 0.614 at 12 months. The scores for year 2, based on collected SF-36 information, were 0.606 at 15 months (based on $N=25$ ), 0.602 at 18 months $(N=23), 0.592$ at 21 months $(N=17)$, and 0.683 at 24 months $(N=15)$.

Using the described extrapolation of quality-of-life scores, and assuming that quality of life for the medical management cohort would remain stable at the baseline level, the undiscounted QALY gain for the SPG stimulation cohort was 0.086 in year 1 , and 0.066 in each following year through year 5 . The resulting discounted QALY gain over 5 years was 0.325 .

As a result of the overall savings and projected QALY gains associated with stimulation the incremental costeffectiveness ratio (ICER) at 5 years was $€ 2,736$ per QALY gained (see Table 3). 
Table 3 Health outcomes and incremental cost-effectiveness results at 5 years

\begin{tabular}{|c|c|c|c|c|c|c|c|}
\hline & \multicolumn{3}{|c|}{ Costs $(€)$} & \multicolumn{3}{|c|}{ Effects (QALYs) } & \multirow[t]{2}{*}{ ICER (€/QALY) } \\
\hline & $\overline{S P G}$ & Control & Difference & $\overline{S P G}$ & Control & Difference & \\
\hline Base case, 5 years, discounted & 42,187 & 41,298 & +889 & 2.87 & 2.55 & 0.32 & 2,736 \\
\hline Base case, 5 years, undiscounted & 42,998 & 44,475 & $-1,477$ & 3.09 & 2.74 & 0.35 & $<0$; SPG dominating \\
\hline
\end{tabular}

\section{Uncertainty analyses}

Table 4 provides an overview of the most relevant scenario results, including the discounted ICERs and discounted cost differences for SPG stimulation versus medical management at 5 years. The cost-effectiveness projections were found to be robust across a wide range of assumptions, including variations in pharmaceutical costs, attack frequency, and the assumed percentage of frequency responders among stimulation patients.

Reducing the timeframe of the analysis to a follow-up period of 3.5 years resulted in an ICER of $€ 40,058$, at an added discounted cost of $€ 9,537$. When the timeframe of the study was increased to 7.0 years, SPG was dominating, at a total discounted savings of $€ 9,857$. Figure 2 provides an overview of the ICER results for the various timeframes considered.

\section{Discussion}

While cluster headache patients have benefitted from some meaningful advances in drug therapy since the 1990s, when injectable and intranasal triptans were introduced, no substantial improvements in pharmaceutical therapy have been made since. As a result, a sizable number of $\mathrm{cCH}$ attacks remain insufficiently treated, and drug therapy alone has been unable to achieve pain relief sufficiently. At the same time, currently used medications, both abortive and prophylactic, are associated with a number of potential severe side effects and tolerability concerns, including increased risk of cardiac events [16, 17] and hypertension [18].

Furthermore, [16-20] injectable triptans are frequently associated with "triptan sensations," characterized by distressing chest discomfort, palpitations, and flushing.

Table 4 Sensitivity analyses: key scenarios and corresponding ICERs and absolute cost differences for SPG versus medical management cohorts

\begin{tabular}{|c|c|c|}
\hline Scenario & $\begin{array}{l}\text { ICER } \\
(€ / Q A L Y)\end{array}$ & $\begin{array}{l}\text { Absolute cost difference, } \\
\text { SPG vs. control (€) }\end{array}$ \\
\hline Base case & 2,736 & +889 \\
\hline Base case (undiscounted) & SPG dominating & $-1,477$ \\
\hline Pain relief $50.2 \%$ (lower bound of $95 \%$ Cl) & 18,846 & 6,125 \\
\hline Pain relief $80.5 \%$ (upper bound of $95 \% \mathrm{Cl}$ ) & SPG dominating & $-3,262$ \\
\hline $1.37 \mathrm{CH}$ attacks per day (50 \% of baseline) & 50,590 & 16,442 \\
\hline $4.11 \mathrm{CH}$ attacks per day (150 \% of baseline) & SPG dominating & $-14,664$ \\
\hline Utilization (cost) of attack-ending meds $+25 \%$ & SPG dominating & $-6,887$ \\
\hline Utilization (cost) of attack-ending meds $-25 \%$ & $€ 26,663$ & 8,665 \\
\hline No frequency response considered for SPG & 13,180 & 4,284 \\
\hline Average frequency reduction low (15\%) & 8,126 & 2,641 \\
\hline Average frequency reduction high (50 \%) & SPG dominating & $-1,191$ \\
\hline No annual change in frequency response & 220 & 72 \\
\hline $\begin{array}{l}\text { Absolute annual reduction in frequency response of } 6.2 \% \text { (double of base case assumption } \\
\text { of } 3.1 \% \text { ) }\end{array}$ & 5,251 & 1,707 \\
\hline $\begin{array}{l}\text { Sumatriptan s.c. used by every patient (at dosage reported by [7], frequency-adjusted to } \\
\text { Pathway } \mathrm{CH}-1 \text {; total medication cost per attack: } € 18.81 \text { ) }\end{array}$ & SPG dominating & $-33,609$ \\
\hline $\begin{array}{l}\text { Every attack treated by maximum guideline-defined medication dosages (total medication } \\
\text { cost per attack: €56.66) }\end{array}$ & SPG dominating & $-165,618$ \\
\hline $\begin{array}{l}\text { Assumption that stimulation device in required revisions would be paid by payers, as } \\
\text { opposed to the manufacturer }\end{array}$ & 12,351 & 4,014 \\
\hline Reduced timeframe of analysis 3.5 years & 40,058 & 9,537 \\
\hline Extended timeframe of analysis 7.0 years & SPG dominating & $-9,857$ \\
\hline
\end{tabular}

Unless otherwise noted, discounting of $3 \%$ is applied on all costs and effects 


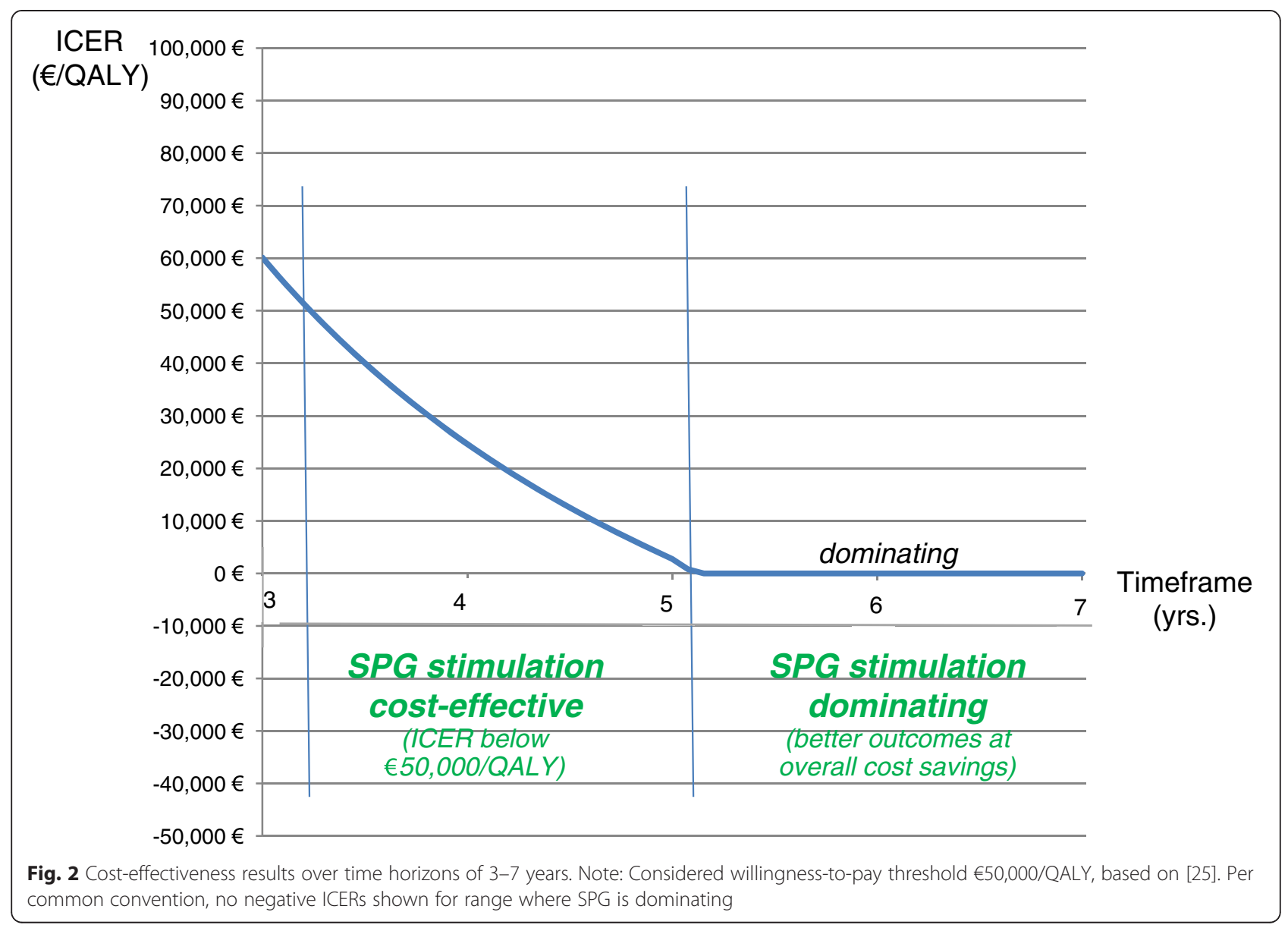

Patients with more frequent cluster attacks per day are unable to use triptans because of the dose limit they can use in a $24 \mathrm{~h}$ period. In addition, triptan treatment is contraindicated for patients with cardiovascular disease, and around $10 \%$ to $20 \%$ of patients are not effectively treated by-or are resistant to-these therapies. High doses of preventive medications like verapamil have the potential to cause serious cardiac abnormalities, including bradycardia, heart blocks and severe hypotension needing aggressive and expensive interventions. Also, lithium is frequently not well tolerated and requires careful medical management of the patients. Topiramate is increasingly used but due to central side effects is not well tolerated by a substantial number of patients. Some patients respond only to corticosteroids, or need them frequently because other preventative medications are not effective throughout the therapy; in these patients severe side effects are unavoidable. Methysergide and injectable dihydroergotramine are rather effective in cluster headache therapy but currently unavailiable in most countries.

As a result, there is a continued need for improved or complementary treatment approaches for $\mathrm{cCH}$ patients. This pressing clinical need is further underscored by a recent study reporting the burden of $\mathrm{cCH}$ to patients and society: more than $50 \%$ of $\mathrm{cCH}$ patients reported suffering symptoms of depression; $25 \%$ were found to have suicidal tendencies; and about $25 \%$ received some form of disability allowance [21].

SPG stimulation using a permanent implantable neurostimulation system has recently been demonstrated to be a safe and effective treatment alternative that offers acute pain relief at effectiveness levels comparable to the latest drug therapies, while also having the beneficial effect of reducing the frequency of attacks $[8,10]$. To-date, it is the only therapy that has the potential of dual benefits of acute pain relief and a reduction in attack frequency, combined with a reduction in overall medication use [10].

The costs of current drug treatments for $\mathrm{cCH}$ are staggering, averaging more than $€ 12,000$ per patient per year for acute medications alone. SPG stimulation has the potential to lower these costs, by reducing or eliminating the need for attack-ending medications, and by achieving preventive effects [8-10].

At the same time, implantation of an SPG stimulation system is a significant one-time investment for payers upfront, averaging more than $€ 30,000$ for implantation, when the costs of the device and the implantation 
procedure are considered. Understanding the healtheconomic profiles of a drug-based treatment strategy versus an implantable neurostimulation strategy is therefore essential to inform decision-making by payers and providers.

Despite the upfront costs for the device and implantation, our analysis showed that SPG stimulation has the potential to be cost-effective in time frames as short as 3 years, and to reduce overall costs to payers in timeframes greater than 5 years, primarily through the reduced need for rescue medications, but also by means of its observed preventive effects.

The results of this study compare favorably to the cost-effectiveness findings for a number of well-accepted and currently reimbursed implantable neurostimulation systems used to treat other clinical conditions with high disease and cost burden, including deep brain stimulation for movement disorders [22], spinal cord stimulation for failed back syndrome [23], and cochlear implants [24]. These comparable therapies have been found to be cost-effective, in that their increased upfront costs have been shown to be associated with improved outcomes that healthcare systems considered a worthy investment.

But none of those technologies were found to bring about cost savings at time horizons as short as those projected in our analysis of SPG stimulation. While the assessment methods used in these published studies resemble our own-in that the results were derived from model-based projections informed by shorter-term clinical trial results-the timeframes adopted for those analyses were a minimum of 5 years, and sometimes a lifetime horizon. The timeframe of 5 years used in our analysis is therefore conservative. Longer follow-up would have led to an even more favorable healtheconomic profile. This fact is worth noting in light of the relatively young age of $\mathrm{cCH}$ patients, as evidenced by the average age of 45 years for the subjects included in Pathway $\mathrm{CH}-1$.

The results of our sensitivity analyses show effects on the cost-effectiveness profile of SPG stimulation that-directionally-would be expected. In the control cohort, higher baseline attack frequency leads to additional savings because more attacks need to be treated with medications. In the SPG stimulation cohort, higher SPG therapy effectiveness leads to overall cost savings at follow-up longer than 5 years, while lower therapy effectiveness reduces the cost-effectiveness, as evidenced by an increased ICER. However, it is noteworthy that SPG stimulation remained cost-effective or cost saving across all trial-informed scenarios, even when considering the lower bound of the $95 \%$ confidence interval for therapy effectiveness reported in the Pathway CH-1 study.
Our study is subject to a number of limitations. First, the Pathway $\mathrm{CH}-1$ study, while randomized and shamcontrolled, included only 28 patients. As a result, our trial-informed base case assumption of $67.1 \%$ pain relief will need to be confirmed by future studies with a larger sample size. Further, the $\mathrm{CH}-1$-observed distribution suggests significant patient-to-patient variation in response to stimulation. In order to test the effect of this uncertainty, we ran scenario-analyses using the lower and upper bound of the $95 \%$ confidence interval of this parameter $(50.2 \%-80.5 \%)$. Even at the lower efficacy assumption, SPG stimulation was found cost-effective, with an ICER of $€ 18,846$ per QALY gained-well below commonly acknowledged willingness-to-pay thresholds. At the higher assumption, SPG stimulation was the dominating strategy, and was associated with overall savings of $€ 3,262$. Similar findings hold for the secondary effectiveness parameter, frequency response.

Second, our analysis assumes the primary treatment effect of pain relief observed in the Pathway $\mathrm{CH}-1$ study is maintained over the full time horizon of the analysis, while the secondary treatment effect of frequency reduction is gradually declining. Even though follow-up data through 24 months are available and there is no evidence or clinical rationale that would support a contrary assumption, further follow-up data will be desirable to confirm our assumptions. The same holds for the assumed longevity of the device. Our scenarios of lower and higher treatment effectiveness-albeit constant-provide insight into the potential effects of gradual changes in primary pain relief over time, and of more or less pronounced reductions in frequency response.

Third, our assumptions about medication use in the control cohort were based on a prior publication reporting on drug usage in a cohort of $\mathrm{cCH}$ patients treated in a tertiary headache center. While these patients share mostly comparable characteristics with the Pathway $\mathrm{CH}$ 1 cohort, and more broadly with patients eligible for SPG stimulation, some variation might exist in actual drug usage. To account for this uncertainty, we considered two scenarios in sensitivity analyses that assumed drug utilization increased or reduced by $25 \%$ from baseline, respectively. Further, our model assumed that attacks successfully treated with SPG stimulation would not require any attack-aborting medication, and that patients not successfully treated would revert to the standard regimen of attack-aborting drugs. While this assumption is in line with the Pathway $\mathrm{CH}-1$ study protocol, individual patient utilization might differ.

Fourth, the control cohort used in our model was defined as sharing the same characteristics as the SPG stimulation cohort at baseline, both in terms of attack frequency and health-related quality of life, and maintaining these parameters constantly over the horizon of 
the analysis. While this assumption seems reasonable, some fluctuations in the patients' severity of $\mathrm{cCH}$ might occur, leading to higher or lower costs and quality of life. However, these potential fluctuations could be expected to occur in both the simulated control cohort and the SPG stimulation cohort, reducing the impact of any such fluctuations on the results of this analysis.

Fifth, our analysis does not consider the potential beneficial health impact of reductions in drug utilization for patients receiving SPG stimulation. Reducing the use of triptans and other attack-ending medications by more than $50 \%$ might lead to fewer drug-related side effects. Including these beneficial effects would have made the health-economic profile of SPG stimulation more favorable.

Sixth, our economic analysis is limited to direct medical cost, that is, costs directly related to medical treatments. The preventative effects, reduction in necessary medication use, and improvement in health-related quality of life demonstrated in Pathway $\mathrm{CH}-1$, however, might lead to reduced absenteeism, increased productivity, and other societal benefits not accounted for in our analysis. Including these potential benefits - again - would have increased the overall savings associated with SPG stimulation and would have further improved the favorable health-economic profile of this therapy choice.

Finally, intangible benefits such as potential therapyrelated reductions in suicidal ideations and improved family/social interactions are not considered in this analysis.

\section{Conclusions}

In summary, our findings suggest that SPG stimulation is a cost-effective treatment strategy for chronic cluster headache patients in the context of the German healthcare system. Adopting this strategy may lead to clinically relevant increases in health-related quality of life, and to overall cost savings for the healthcare system at timeframes longer than 5 years. Further clinical data are needed to confirm these model-based findings.

\section{Abbreviations \\ ATI: Autonomic Technologies, Inc:; cCH: Chronic cluster headache; CH: Cluster headache; CT: Computed tomography; DVT: Digital volume tomography; ICER: Incremental cost-effectiveness ratio; QALY: Quality-adjusted life year; SF-36: Short-form 36v2; SHI: German statutory health insurance; SPG: Sphenopalatine ganglion.}

\section{Competing interests}

Jan B. Pietzsch, Ph.D.: Dr. Pietzsch is president, CEO, and shareholder of Wing Tech Inc., a technology consulting firm focusing on early-stage assessment of medical technologies. Wing Tech Inc. received consulting fees from Autonomic Technologies Inc. to develop the health-economic model used in this analysis. Abigail Garner, M.S.: Ms. Garner worked as a consultant for Wing Tech Inc. on this project.

Charly Gaul, M.D.: Dr. Gaul received honoraria for participation in clinical trials, contribution to advisory boards or oral presentations from MSD, Berlin Chemie AG, St. Jude Medical, ATI, Electrocore, Complen Health GmbH, Allergan,
Boehringer Ingelheim, Astellas, and Hormosan. He has no ownership interest and does not own stocks of any pharmaceutical company.

Arne May, M.D.: Dr. May is funded by the University Clinic of Hamburg and received unrestricted research support from LindeGas (RealFund) and scientific funds by the Deutsche Forschungsgemeinschaft (DFG) and European Framework (FP7), is or has been consultant or speaker for Pfizer, Bayer Vital, GSK, Allergan, ATI, MSD, Electrocore and Desitin and is an editorial board member of Cephalalgia, J Headache and Pain, European Neurology and Der Schmerz. This work was initiated by the authors and Autonomic Technologies provided support to Wing Tech Inc. (JBP and AMG) for model development and necessary analyses. Autonomic Technologies had no influence on the results or manuscript development. The authors maintained the right to publish without approval of the funding source.

\section{Authors' contributions}

JBP conceived of the study, participated in the study design and model construction, and drafted the manuscript. AM participated in the study design, critically reviewed the model and assumptions, and helped with drafting the manuscript. CG participated in the study design, critically reviewed the model and assumptions, and helped with drafting the manuscript. AMG conducted literature review and data searches and helped with drafting the manuscript. All authors read and approved the final manuscript.

\section{Author details}

${ }^{1}$ Wing Tech Inc., Menlo Park, CA, USA. ${ }^{2}$ Migräne- und Kopfschmerzklinik Königstein, Königstein im Taunus, Germany. ${ }^{3}$ Institut für Systemische Neurowissenschaften, Universitätsklinikum Hamburg-Eppendorf, Martinistr. 52, Haus S10, Zi. 318, Hamburg 20246, Germany.

Received: 17 February 2015 Accepted: 5 May 2015

Published online: 21 May 2015

\section{References}

1. Headache Classification Committee of the International Headache S (2013) The international classification of headache disorders, 3rd edition (beta version). Cephalalgia 33(9):629-808, doi:10.1177/0333102413485658

2. Headache Classification Subcommittee of the International Headache Society (2004) The International Classification of Headache Disorders: 2nd edition. Cephalalgia 24(1):9-160

3. Goadsby PJ (2002) Pathophysiology of cluster headache: a trigeminal autonomic cephalgia. Lancet Neurol 1(4):251-257

4. Freitag FG, Schloemer $F$ (2014) Medical management of adult headache Otolaryngol Clin North Am 47(2):221-237, doi:10.1016/j.otc.2013.11.002

5. May A, Leone M, Afra J, Linde M, Sandor PS, Evers S, Goadsby PJ (2006) EFNS guidelines on the treatment of cluster headache and other trigeminal-autonomic cephalalgias. Eur J Neurol 13(10):1066-1077, doi:10.1111/j.1468-1331.2006.01566.x

6. May A (2005) Cluster headache: pathogenesis, diagnosis, and management. Lancet 366(9488):843-855, doi:10.1016/S0140-6736(05)67217-0

7. Gaul C, Finken J, Biermann J, Mostardt S, Diener HC, Muller O, Wasem J, Neumann A (2011) Treatment costs and indirect costs of cluster headache: a health economics analysis. Cephalalgia 31(16):1664-1672, doi:10.1177/ 0333102411425866

8. Schoenen J, Jensen RH, Lanteri-Minet M, Lainez MJ, Gaul C, Goodman AM, Caparso A, May A (2013) Stimulation of the sphenopalatine ganglion (SPG) for cluster headache treatment. Pathway $\mathrm{CH}-1$ : a randomized, sham-controlled study. Cephalalgia 33(10):816-830, doi:10.1177/0333102412473667

9. Láinez JJ, May A, Gaul C, Goodman A, Caparso A, Schoenen J (2014) Efficacy of SPG stimulation in relieving acute cluster pain: results from $>5000$ attacks treated during long-term follow-up of the pathway $\mathrm{CH}-1$ study. Paper presented at the accepted for presentation at 4th European Headache and Migraine Trust International Congress (EHMTIC), Copenhagen, Denmark, 18-21September 2014

10. Láinez JJ, Schoenen J, Gaul C, Lantéri-Minet M, Goodman A, Caparso A, May A (2014) Sphenopalatine Ganglion Stimulation (SPGS) for Chronic Cluster Headache $(\mathrm{CH})$ treatment - change in Preventive Medication (PM) use at 1 year in the pathway $\mathrm{CH}-1$ study. Paper presented at the presentation at AHS 2014 - American Headache Society 56th Annual Scientific Meeting, Los Angeles, CA, USA, 26-29 June 2014 
11. Cohen DJ, Reynolds MR (2008) Interpreting the results of cost-effectiveness studies. J Am Coll Cardiol 52(25):2119-2126, doi:10.1016/j.jacc.2008.09.018

12. Gold M, Siegel J, Russell L, Weinstein M (1996) Cost-effectiveness in health and medicine. Oxford University Press, New York

13. Weinstein MC, O'Brien B, Hornberger J, Jackson J, Johannesson M, McCabe C, Luce BR, Studies ITFoGRP-M (2003) Principles of good practice for decision analytic modeling in health-care evaluation: report of the ISPOR task force on good research practices-modeling studies. Value in health: the journal of the International Society for Pharmacoeconomics and Outcomes Research 6(1):9-17

14. Rote Liste (2014) Rote Liste Service GmbH 1. ISBN: 978-3-939192-80-0

15. Ara R, Brazier J (2008) Deriving an algorithm to convert the eight mean SF-36 dimension scores into a mean EQ-5D preference-based score from published studies (where patient level data are not available). Value in health: the journal of the International Society for Pharmacoeconomics and Outcomes Research 11(7):1131-1143, doi:10.1111/j.1524-4733.2008.00352.x

16. Barra S, Lanero S, Madrid A, Materazzi C, Vitagliano G, Ames PR, Gaeta G (2010) Sumatriptan therapy for headache and acute myocardial infarction. Expert Opin Pharmacother 11(16):2727-2737, doi:10.1517/14656566.2010.522567

17. Stillman MJ, Tepper DE, Tepper SJ, Cho L (2013) QT prolongation, Torsade de Pointes, myocardial ischemia from coronary vasospasm, and headache medications. Part 2: review of headache medications, drug-drug interactions, QTc prolongation, and other arrhythmias. Headache 53(1):217-224, doi:10.1111/j.1526-4610.2012.02299.x

18. Vanmolkot FH, de Hoon JN (2006) Acute effects of sumatriptan on aortic blood pressure, stiffness, and pressure waveform. Clin Pharmacol Ther 80(1):85-94, doi:10.1016/j.clpt.2006.03.011

19. Gardner DM, Lynd LD (1998) Sumatriptan contraindications and the serotonin syndrome. Ann Pharmacother 32(1):33-38

20. Nezvalova-Henriksen K, Spigset O, Nordeng H (2013) Triptan safety during pregnancy: a Norwegian population registry study. Eur J Epidemiol 28(9):759-769, doi:10.1007/s10654-013-9831-x

21. Jurgens TP, Gaul C, Lindwurm A, Dresler T, Paelecke-Habermann $Y$, Schmidt-Wilcke T, Lurding R, Henkel K, Leinisch E (2011) Impairment in episodic and chronic cluster headache. Cephalalgia 31(6):671-682, doi:10.1177/0333102410391489

22. Eggington S, Valldeoriola F, Chaudhuri KR, Ashkan K, Annoni E, Deuschl G (2014) The cost-effectiveness of deep brain stimulation in combination with best medical therapy, versus best medical therapy alone, in advanced Parkinson's disease. J Neurol 261(1):106-116, doi:10.1007/s00415-013-7148-z

23. Taylor RS, Ryan J, O'Donnell R, Eldabe S, Kumar K, North RB (2010) The cost-effectiveness of spinal cord stimulation in the treatment of failed back surgery syndrome. Clin J Pain 26(6):463-469, doi:10.1097/ AJP.0b013e3181daccec

24. Bond M, Mealing S, Anderson R, Elston J, Weiner G, Taylor RS, Hoyle M, Liu Z, Price A, Stein K (2009) The effectiveness and cost-effectiveness of cochlear implants for severe to profound deafness in children and adults: a systematic review and economic model. Health Technol Assess 13(44):1-330, doi:10.3310/hta13440

25. WHO (2003) Making choices in health: WHO guide to cost-effectiveness analysis. World Health Organization, Geneva

26. Personal communication. Information provided by Autonomic Technologies, Inc (ATI) (2014).

27. Bundesvereinigung K (2014) Einheitlicher Bewertungsmasstab (EBM), 1. Quartal. See http://www.kbv.de/media/sp/Einheitlicher_Bewertungsma_stab_Stand 2014_1._Quartal.pdf

\section{Submit your manuscript to a SpringerOpen ${ }^{\odot}$ journal and benefit from:}

- Convenient online submission

- Rigorous peer review

- Immediate publication on acceptance

- Open access: articles freely available online

- High visibility within the field

- Retaining the copyright to your article

Submit your next manuscript at $>$ springeropen.com 